\title{
AN APPROACH USING LAGRANGIAN/SURROGATE RELAXATION FOR LOT-SIZING WITH TRANSPORTATION COSTS
}

\author{
Flavio Molina \\ Departamento de Engenharia de Produção \\ Universidade Federal de São Carlos (UFSCar) \\ São Carlos - SP \\ flaviomolinabr@yahoo.com.br
}

Maristela Oliveira dos Santos*

Franklina M. B. Toledo

Dep. de Matemática Aplicada e Estatística / ICMC

Universidade de São Paulo (USP)

São Carlos - SP

mari@icmc.usp.br; fran@icmc.usp.br

\section{Silvio Alexandre de Araujo}

Dep. de Ciências da Computação e Estatística / IBILCE

Universidade Estadual Paulista (UNESP)

São José do Rio Preto - SP

saraujo@ibilce.unesp.br

* Corresponding author / autor para quem as correspondências devem ser encaminhadas

Recebido em 04/2007; aceito em 10/2008 após 1 revisão

Received April 2007; accepted October 2008 after one revision

\begin{abstract}
The aim of this work was to study a distribution and lot-sizing problem that considers costs with transportation to a company warehouse as well as, inventory, production and setup costs. The logistic costs are associated with necessary containers to pack produced items. The company negotiates a long-term contract in which a fixed cost per period is associated with the transportation of the items. On the other hand, a limited number of containers are available with a lower cost than the average cost. If an occasional demand increase occurs, other containers can be utilized; however, their costs are higher. A mathematical model was proposed in the literature and solved using the Lagrangian heuristic. Here, the use of the Lagrangian/ surrogate heuristic to solve the problem is evaluated. Moreover, an extension of the literature model is considered adding capacity constraints and allowing backlogging. Computational tests show that Lagrangian/ surrogate heuristics are competitive, especially when the capacity constraints are tight.
\end{abstract}

Keywords: lot-sizing; transportation costs; Lagrangian/surrogate relaxation.

\section{Resumo}

Neste trabalho estuda-se um problema de dimensionamento de lotes e distribuição que envolve além de custos de estoques, produção e preparação, custos de transportes para o armazém da empresa. Os custos logísticos estão associados aos contêineres necessários para empacotar os produtos produzidos. A empresa negocia um contrato de longo prazo onde um custo fixo por período é associado ao transporte dos itens, em contrapartida um limite de contêineres é disponibilizado com custo mais baixo que o custo padrão. Caso ocorra um aumento ocasional de demanda, novos contêineres podem ser utilizados, no entanto, seu custo é mais elevado. Um modelo matemático foi proposto na literatura e resolvido utilizando uma heurística Lagrangiana. No presente trabalho a resolução do problema por uma heurística Lagrangiana/surrogate é avaliada. Além disso, é considerada uma extensão do modelo da literatura adicionando restrições de capacidade e permitindo atraso no atendimento a demanda. Testes computacionais mostraram que a heurística Lagrangiana/surrogate é competitiva especialmente quando se têm restrições de capacidade apertada.

Palavras-chave: dimensionamento de lotes; custos de transporte; relaxação Lagrangiana/surrogate. 


\section{Introduction}

Transportation costs account for a substantial part of the total logistics costs of a product. Nevertheless, they are often neglected in the literature regarding lot-sizing. In general, the costs considered by lot-sizing models are restricted to production, inventory and setup. Some recent reviews of lot-sizing problems can be found in Karimi et al. (2003) and Brahimi et al. (2006).

Vroblefski et al. (2000) say that transportation costs are one of the highest costs in the logistics of distributed warehousing. According to them, these costs are volume-dependent. Baumol \& Vinod (1970) use the inventory theory to analyze some trade-offs among transportation attributes: freight rates, speed, dependability (variance in speed) and en-route loss. Lee (1989) considered a dynamic lot-sizing model allowing multiple setup costs including a fixed charge cost and a freight cost, where a fixed single container type with limited carrying capacity is considered and the freight cost is proportional to the number of containers used. Lee et al. (2005) extend the previous paper (Lee, 1989) considering multiple items. These authors proposed a heuristic based on the representation of the problem as a network flow model. Norden \& Velde (2005) argue that the freight rates depend on the kind of contract established with the logistics service, i.e., they are not exclusively dependent on the volume to be transported.

The model proposed by Norden \& Velde (2005) takes into account a real problem of a European company with heavily fluctuating monthly shipments between its manufacturing plant and its central warehouse. The company has a long-term contract, which combines two buying strategies: systematic (to cover longer-term needs) and spot (to cover immediate needs). The contract has a fixed cost per period and a limited number of lower cost containers. The limited number of containers is based on demand. If the demand increases, extra containers can be used, but at a higher price. The aim is to minimize production and distribution costs. The authors propose a Lagrangian heuristic to solve the problem.

The studies mentioned above deal with both distribution and production problems in an integrated way. Erenguç et al. (1999) and Rizk \& Martel (2001) present a general review of integrated production/distribution problems and Bertazzi \& Speranza (1999) present a review considering extensions of the classical lot-sizing model for transportation cost models.

Here, we investigate and propose a new solution method to the problem studied by Norden \& Velde (2005). The proposed method consists of a Lagrangian/surrogate heuristic and the computational results are comparable to the Lagrangian heuristic presented by Norden \& Velde (2005). Moreover, the model proposed by Norden \& Velde (2005) is extended adding capacity constraints and allowing backorders.

This paper is structured as follows: Section 2 introduces the extended modeling of the problem proposed by Norden \& Velde (2005). Section 3 describes the proposed heuristics. In Section 4, we discuss the computational results. Conclusions and directions for further research are presented in Section 5.

\section{Mathematical Formulation}

The model studied is based on the model proposed by Norden \& Velde (2005) where the transportation contract established consists of three kinds of costs: a monthly fixed cost of the contract; cost per unit of the first $R$ containers used ( $R$ is defined in the contract and is 
determined based on the item demand estimation); cost per unit of the remaining containers. Based on these values, the cost function to use $r$ containers can be expressed by:

$$
f(r)= \begin{cases}c_{0}+r c_{1} & \text { if } r \leq R \\ c_{0}+R c_{1}+(r-R) c_{2} & \text { otherwise }\end{cases}
$$

where:

$c_{0}$ - monthly fixed cost of the contract;

$c_{1}-$ cost per unit of the first $R$ containers used;

$c_{2}-$ cost per unit of the remaining containers.

The model parameters and variables are defined below.

\section{Parameters:}

$i=1,2, \ldots, n$ Number of distinct items to be produced;

$t=1,2, \ldots, T$ Number of periods in the planning horizon;

$s_{i t} \quad$ Setup cost for the production of item $i$ in period $t$;

$h_{i t}^{+} \quad$ Cost for holding a unit of item $i$ in period $t$;

$h_{i t}^{-} \quad$ Penalty for delaying a unit of item $i$ in period $t$;

$d_{i t} \quad$ Demand of item $i$ in period $t$;

$b_{i} \quad$ Time required to produce an unit of item $i$;

$q_{i} \quad$ Setup time for production of item $i$;

$\mathrm{Cap}_{t} \quad$ Production capacity in period $t$;

$M \quad$ A large positive integer number.

\section{Decision variables:}

$X_{i t} \quad$ Quantity of units of the item $i$ to be produced in period $t$;

$I_{i t}^{+} \quad$ Quantity of units of the item $i$ held at the end of period $t$;

$I_{i t}^{-} \quad$ Quantity of units of the item $i$ delayed at the end of period $t$;

$Y_{i t} \quad$ Binary variable that indicates the setup for producing item $i$ in period $t$; ( $Y_{i t}=1$ if $X_{i t}>0$ and $Y_{i t}=0$, otherwise);

$A_{t} \quad$ Number of containers transported in period $t$ with fee $c_{1}$ (variable);

$B_{t} \quad$ Number of containers transported in period $t$ with fee $c_{2}$ (variable).

The problem is to determine the production of item $i(i=1,2, \ldots, n)$ for each period $t$ $(t=1,2, \ldots, T)$ in the planning horizon in order to satisfy a pre-established demand $d_{i t}$. A fixed setup cost $\left(s_{i t}\right)$ occurs whenever item $i$ is produced in period $t$, i.e. $X_{i t}>0$. The goal is to 
develop a production plan to minimize the sum of storage $\left(h_{i t}^{+}\right)$, delays $\left(h_{i t}^{-}\right)$, preparations and transportations $\left(c_{0}, c_{1}\right.$ and $\left.c_{2}\right)$ costs. In addition, the required time to produce items $\sum_{i=1}^{n} r_{i} X_{i t}$ plus the preparation time spent $\sum_{i=1}^{n} q_{i} Y_{i t}$ should be smaller than the capacity Cap $_{t}$ in each period $t$. In the model, the authors consider that each container (they are all of the same size) can fit $P$ unities of each item, i.e. the items also have the same size. Furthermore, they assume that the orders are placed at the beginning of each period and the items can be used to meet a demand in the same period they are produced. The initial stock and delays of every product are equal to zero. i.e. $I_{i o}^{+}=0$ and $I_{i o}^{-}=0, \forall i$.

The mathematical model is presented below.

$z=\min \sum_{i=1}^{n} \sum_{t=1}^{T}\left(h_{i t}^{+} I_{i t}^{+}+h_{i t}^{-} I_{i t}^{-}+s_{i t} Y_{i t}\right)+\sum_{t=1}^{T}\left(c_{0}+c_{1} A_{t}+c_{2} B_{t}\right)$

subject to

$$
\begin{array}{ll}
I_{i, t-1}^{+}-I_{i, t-1}^{-}+X_{i t}-I_{i t}^{+}+I_{i t}^{-}=d_{i t} & i=1, \ldots n ; \quad t=1, \ldots, T ; \\
X_{i t}-M Y_{i t} \leq 0 & i=1, \ldots n ; \quad t=1, \ldots, T ; \\
\sum_{i=1}^{n}\left(b_{i} X_{i t}+q_{i} Y_{i t}\right) \leq \mathrm{Cap}_{t} & t=1, \ldots, T ; \\
B_{t}+A_{t} \geq \frac{1}{P} \sum_{i=1}^{n} X_{i t} & t=1, \ldots, T ; \\
0 \leq A_{t} \leq R & t=1, \ldots, T ; \\
I_{i 0}^{+}=0, I_{i 0}^{-}=0 & i=1, \ldots, n ; \\
X_{i t} \geq 0, I_{i t}^{+} \geq 0, I_{i t}^{-} \geq 0 & i=1, \ldots, n ; \quad t=1, \ldots, T ; \\
A_{t}, B_{t} \in \mathrm{N}, Y_{i t} \in\{0,1\} & i=1, \ldots, n ; \quad t=1, \ldots, T ;
\end{array}
$$

The objective function (1) minimizes the sum of the inventory, delay, setup, and transportation costs. Constraints (2) ensure that the demand is met. Constraints (3) ensure that the setup cost is considered if production occurs. Constraints (4) are capacity constraints. Constraints (5) make enough number of containers to transport the items feasible. Constraints (6) limit the use of containers with a lower cost according to the contract. Constraints (7) set the initial inventory and delay to zero and constraints (8) ensure that the variable production, inventory, and delay are non-negative. Finally, constraints (9) restrict the values of the binary and integer variables.

Since the cost $\sum_{t=1}^{T} c_{0}$ is constant and does not depend on the decision made, it will be omitted. For this model, $M$ will be fixed as the sum of the demands of all items in the planning horizon, i.e., $M=\sum_{t=1}^{T} \sum_{i=1}^{n} d_{i t}$. Norden \& Velde (2005) proved that the model without capacity constraints is $N P$-hard. 


\section{Solution Method}

A heuristics based on Lagrangian relaxation combined with Surrogate relaxation was developed in order to solve transportation cost lot-sizing problems (LSP) discussed earlier. Narciso \& Lorena (1999) provide a theoretical development of the combined Lagrangian/ surrogate relaxation.

Lagrangian relaxation, introduced by Held \& Karp (1971) (see also the classic work of Geoffrion (1974) and Fisher (1981)) has been widely used in different areas including lot-sizing (see Trigeiro et al., 1989; Lozano et al., 1991; Diaby et al., 1992; and Toledo \& Armentano, 2006).

Glover (1965) and Glover (1968) introduced the surrogate relaxation and theoretical studies were published by Greenberg \& Pierskalla (1970), Greenberg \& Pierskalla (1973) and Glover (1975). Due to the successes of Lagrangian relaxation and to the difficulties to obtain limits for surrogate relaxation, the latter has been less commonly used than the former. Nevertheless, Greenberg \& Pierskalla (1970) present an important result ensuring that the surrogate relaxation duality gap is equal to or less than the Lagrangian relaxation duality gap. This fact has motivated several researchers to keep on studying the surrogate relaxation. Hence, there have been studies on the integrated Lagrangian/surrogate relaxation (Karwan \& Rardin, 1979). Narciso (1998) proposed Lagrangian/surrogate relaxation and applied it to the generalized assignment problem and to the travelling salesman problem. This relaxation consists of two steps: in Step 1, the surrogate relaxation is applied to a set of constraints, to which surrogate multipliers are associated resulting in only one surrogate constraint; in Step 2 , the Lagrangian relaxation is applied to the surrogate constraint with an associated Lagrangian multiplier. The result is a Lagrangian problem with a one-dimensional multiplier. Other applications of the Lagrangian/surrogate relaxation were reported by Narciso \& Lorena (1999) who studied the one-dimensional generalized assignment problem; Senne \& Lorena (2000) who dealt with the p-Median problem; Lorena \& Pereira (2002) who considered the maximal covering problem; and Oliveira \& Morabito (2006) who focused on the container loading. However, no application of the Lagrangian/surrogate relaxation to the lot-sizing problem was found in the literature.

\subsection{Lagrangian/surrogate relaxation}

Initially the model (1)-(9) is considered and the Surrogate relaxation for the constraints sets (4) and (5) is proposed. Next, the Lagrangian relaxation of the surrogate constraint is made. To obtain the surrogate relaxation of problem (1)-(9), the multipliers $\lambda=\left(\lambda_{1}^{1}, \cdots, \lambda_{T}^{1}, \lambda_{1}^{2}, \cdots, \lambda_{T}^{2}\right) \geq 0$ were used associated to the constraints (4) and (5) and the following surrogate relaxation is obtained:

$$
\begin{aligned}
V\left(S u_{\lambda}\right)= & \min \sum_{i=1}^{n} \sum_{t=1}^{T}\left(h_{i t}^{+} I_{i t}^{+}+h_{i t}^{-} I_{i t}^{-}+s_{i t} Y_{i t}\right)+\sum_{t=1}^{T}\left(c_{0}+c_{1} A_{t}+c_{2} B_{t}\right) \\
& \text { subject to } \\
& \text { (2)-(3); (6)-(9) } \\
& \sum_{t=1}^{T} \sum_{i=1}^{n}\left(\frac{\lambda_{t}^{1} X_{i t}}{P}+\lambda_{t}^{2}\left(b_{i} X_{i t}+q_{i} Y_{i t}\right)\right) \leq \sum_{t=1}^{T}\left(\lambda_{t}^{1}\left(A_{t}+B_{t}\right)+\lambda_{t}^{2} \operatorname{Cap}_{t}\right)
\end{aligned}
$$


Constraint (10) is a relaxation of the number of containers required to transport the items and of the capacity required to produce the items in each period. However, it ensures that the total sum of the containers and capacity is sufficient for transporting and producing all the items in the planning horizon. The outcome of surrogate relaxation is not easy to solve since the decision variables $X_{i t}$ remain integrated by the knapsack constraint (10), and therefore it cannot be separated into independent subproblems preventing the application of well-known methods of the literature. In order to obtain a solution, the Lagrangian relaxation of the surrogate constraint (10) of the relaxation problem is proposed. Therefore, after relaxing the surrogate constraint, the Lagrangian/surrogate is obtained as follows:

$$
V\left(L_{\mu} S u_{\lambda}\right)=\min \sum_{i=1}^{n} \sum_{t=1}^{T}\left(h_{i t}^{*+} I_{i t}^{+}+h_{i t}^{*-} I_{i t}^{-}+s_{i t}^{*} Y_{i t}\right)+\sum_{t=1}^{T}\left(\left(c_{1}-\mu \lambda_{t}^{1}\right) A_{t}+\left(c_{2}-\mu \lambda_{t}^{1}\right) B_{t}\right)+C
$$

subject to

$(2)-(3) ;(6)-(9)$

where:

$$
\begin{aligned}
& C=\mu \sum_{t=1}^{T}\left(\sum_{i=1}^{n} d_{i t}\left(\frac{\lambda_{t}^{1}}{P}+\lambda_{t}^{2} b_{i}\right)-\lambda_{t}^{2} \operatorname{Cap}_{t}\right) \\
& h_{i t}^{*+}=h_{i t}^{+}+\frac{\mu \lambda_{t}^{1}-\mu \lambda_{t+1}^{1}}{P}+\mu b_{i}\left(\lambda_{t}^{2}-\lambda_{t+1}^{2}\right) \text { and } \lambda_{T+1}^{1}=\lambda_{T+1}^{2}=0 . \\
& h_{i t}^{*-}=h_{i t}^{-}+\frac{\mu \lambda_{t+1}^{1}-\mu \lambda_{t}^{1}}{P}+\mu b_{i}\left(\lambda_{t+1}^{2}-\lambda_{t}^{2}\right) \text { and } \lambda_{T+1}^{1}=\lambda_{T+1}^{2}=0 . \\
& s_{i t}^{*}=s_{i t}+\mu \lambda_{t}^{2} q_{i}
\end{aligned}
$$

The value of the objective function (11) of the relaxed problem $V\left(L_{\mu} S u_{\lambda}\right)$ gives a lower bound for the original problem. Given a certain value $\mu$, the outcome is a Lagrangian problem that can be solved using the subgradient method. It is worth mentioning that if $\mu=1$, the Lagrangian relaxation of the original problem is obtained. The decision variables $X_{i t}$ in the problem $V\left(L_{\mu} S u_{\lambda}\right)$ are no longer integrated (as in the Norden \& Velde (2005) problem). Therefore, for the fixed values of $\mu$ and $\left(\lambda_{1}^{1}, \cdots, \lambda_{T}^{1}, \lambda_{1}^{2}, \cdots, \lambda_{T}^{2}\right)$ it can be separated into two independent subproblems: the lot-sizing subproblem and transportation subproblem.

\subsubsection{Lot sizing subproblem}

The first subproblem, obtained using the Lagrangian/surrogate relaxation, is a lot-sizing problem without capacity constraints. The objective function costs are defined by the Lagrangian multiplier and surrogate multipliers. This problem can be divided into one lotsizing problem for each item as shown below. The optimum solution $\left(V\left(S u b_{1 i}\right)\right.$ can be easily obtained using the Zangwill (1969) algorithm. 


$$
\begin{aligned}
& V\left(S u b_{1 i}\right)=\min \sum_{t=1}^{T}\left(h_{i t}^{*+} I_{i t}^{+}+h_{i t}^{*-} I_{i t}^{-}+s_{i t}^{*} Y_{i t}\right) \\
& \text { subject to } \\
& I_{i, t-1}^{+}-I_{i, t-1}^{-}+X_{i t}-I_{i, t}^{+}+I_{i, t}^{-}=d_{i t} \quad t=1, \ldots, T ; \\
& X_{i t}-M Y_{i t} \leq 0 \quad t=1, \ldots, T \text {; } \\
& I_{i 0}^{+}=0, I_{i 0}^{-}=0 \text {, } \\
& X_{i t} \geq 0, I_{i t}^{+} \geq 0, I_{i t}^{-} \geq 0 \quad t=1, \ldots, T ; \\
& Y_{i t} \in\{0,1\} \quad t=1, \ldots, T \text {. }
\end{aligned}
$$

\subsubsection{Transportation subproblem}

The transportation subproblem, obtained after applying Lagrangian/surrogate relaxation, can be expressed as follows:

$$
V\left(S u b_{2}\right)=\min \sum_{t=1}^{T}\left(\left(c_{1}-\mu \lambda_{t}^{1}\right) A_{t}+\left(c_{2}-\mu \lambda_{t}^{1}\right) B_{t}\right)
$$

subject to

$$
\begin{array}{ll}
0 \leq A_{t} \leq R & t=1, \ldots T \\
A_{t}, B_{t} \in \mathrm{N} & t=1, \ldots T .
\end{array}
$$

The resolution of $V\left(S u b_{2}\right)$ can be obtained by inspection, that is, if $\left(\left(c_{1}-\mu \lambda_{t}^{1}\right)<0\right.$ for some period $t$, then let $A_{t}=R$, otherwise, let $A_{t}=0$. Moreover, if $\left(\left(c_{2}-\mu \lambda_{t}^{2}\right)<0\right.$ for some period $t$, then let $B_{t} \rightarrow \infty$, otherwise let $B_{t}=0$. However, if $t$ exists with $\left(\left(c_{2}-\mu \lambda_{t}^{2}\right)<0\right.$, then the bound obtained by this procedure will be not be useful $(-\infty)$.

In order to improve the quality of these lower bounds, Norden \& Velde (2005) propose bounds for variables $B_{t}$ and some valid inequalities. However, due to the generalizations considered in the model (1)-(9) (backlogging and capacity constraints), the bounds for the variables $B_{t}$ and the inequalities proposed by Norden \& Velde (2005) are no longer valid for the model of this paper. Next, we present a new bound for the variables $B_{t}$ and a new valid inequality.

\section{- Upper bounds on $B_{t}$ variables}

Consider restriction (5) again: $B_{t}+A_{t} \geq \frac{1}{P} \sum_{i=1}^{n} X_{i t}$.

Observe that in the considered production process, the whole production of a given period must be transported by the containers. Moreover, no item in the stock to be transported exists coming from a previous period. This implies that the quantity of containers needed in a given period will never exceed the quantity required for the transportation of all the items produced in this period. 
The basic idea in the bounds proposed by Norden \& Velde (2005) consists of limiting $B_{t}$ based on the demand in period $t$ until the end of the time horizon. As there is no backlog, the maximal production in period $t$ is bonded according to this value. However, as we admit delays in the model (1)-(9), the production of a given period may be equal to the sum of the demand of the whole time horizon. In order to determine a bound for $B_{t}$, consider $U D$ as the number of containers needed to transport the demand of all the items in all the periods:

$$
U D=\left\lceil\sum_{t=1}^{T} \sum_{i=1}^{n} \frac{d_{i t}}{P}\right\rceil .
$$

Then, $B_{t}$ can be limited by $(U D-R)$, where $R$ is the maximal number of lower rate containers which can be used in period $t$. In this work, the capacity of production is restricted then we know that the quantity produced in a given period is also limited. Then, in order to obtain a bound for $B_{t}$, let $q_{\min }$ be the least between the setup times for items $i(i=1, \ldots, n$.), that is, $q_{\min }=\min \left\{q_{i} \mid i=1, \ldots, n\right\}$. Let also $b_{\min }$ be the least production time, that is, $b_{\min }=\min \left\{b_{i} \mid i=1, \ldots, n\right\}$. Define $U C_{t}$ to be the upper bound for the maximal number of containers required in period $t$ :

$$
U C_{t}=\left\lceil\frac{\frac{C a p_{t}-q_{\min }}{b_{\min }}}{P}\right\rceil t=1, \ldots, T
$$

This bound is valid, once that, in a period where some item is produced, the production capacity $\mathrm{Cap}_{t}$ will be reduced by the setup time of this item. Since it is not possible to know which is the produced item (nor how many items are being produced), we consider a unique setup referring to the item with a minimal setup time, resulting in $\left(\mathrm{Cap}_{t}-q_{\min }\right)$. In order to convert the production capacity into the number of items, we divide $\left(\mathrm{Cap}_{t}-q_{\min }\right)$ by the time required to produce a unit of the selected item. In order to ensure the upper bound, we again choose the $b_{\min }$. We have the fact that the maximal number of items that can be produced in a period $t$ is given by $\left(\mathrm{Cap}_{t}-q_{\min }\right) / b_{\min }$. Dividing this value by the number of items which fit in a container $(P)$ and taking the least larger integer, we obtain the maximal number of containers required for period $t$. Therefore, we obtain $B_{t} \leq\left\{U C_{t}-R\right\}$.

Considering both bounds for $B_{t}$ we obtain:

$$
B_{t} \leq \min \left\{U D-R, U C_{t}-R\right\} \quad t=1, \ldots, T
$$

\section{- Valid Inequality}

The inequality (13), adapted from Norden \& Velde (2005) and presented below, ensures that the whole demand will be transported, by means of the lower and high rate containers.

$$
\sum_{t=1}^{T}\left(A_{t}+B_{t}\right) \geq U D
$$

The algorithm for the solution of $V\left(\mathrm{Sub}_{2}\right)$ with the inequalities (12) and (13) is summarised below.

$$
F S_{t}-\text { Number of containers with lower rate unused in period } t
$$


Step $0 \quad F S_{t}=R ; A_{t}=0, B_{t}=0 \quad t=1, \ldots, T$

Step 1 for $t=1, \ldots, T$

$$
\begin{gathered}
\text { if }\left(c_{1}-\mu \lambda_{t}^{1}\right)<0 \text { then } \\
A_{t}=R ; \\
F S_{t}=0 ; \\
U D=U D-A_{t} ; \\
\text { if }\left(c_{2}-\mu \lambda_{t}^{2}\right)<0 \text { then } \\
B_{t}=U C_{t} ; \\
U C_{t}=0 ; \\
U D=U D-B_{t} ;
\end{gathered}
$$

Step 2 Define the set in increasing order as follows:

$$
N C=\left\{\left(c_{1}-\mu \lambda_{t}^{1}\right), t=1, \ldots, T\right\} \cup\left\{\left(c_{2}-\mu \lambda_{t}^{2}\right), t=1, \ldots, T\right\}
$$

Step 3 Select the first element of the set (for a given $t$ ) while $U D>0$ do

If the element is considered the first subset

If the selected element comes from the first subset

then $\quad A_{t}=A_{t}+\min \left\{U D, F S_{t}, U C_{t}\right\}$

$U D=U D-\min \left\{U D, F S_{t}, U C_{t}\right\}$

$F S_{t}=F S_{t}-\min \left\{U D, F S_{t}, U C_{t}\right\}$

$$
U C_{t}=U C_{t}-\min \left\{U D, F S_{t}, U C_{t}\right\}
$$

else

$$
\begin{aligned}
& B_{t}=B_{t}+\min \left\{U D, U C_{t}\right\} \\
& U D=U D-\min \left\{U D, U C_{t}\right\}
\end{aligned}
$$$$
U C_{t}=U C_{t}-\min \left\{U D, U C_{t}\right\}
$$

if $U D<=0$

then stop, the solution is found.

Else choose the next element from set $N C$. end while.

Step 4 Return the values of $A_{t}$ and $B_{t}$.

In this paper, the Lagrangian/surrogate problem will be solved as proposed by Narciso (1998). The author proposes the application of the subgradient method for $k$ iterations for the Lagrangian/surrogate problem with a fixed value for the multiplier $\mu$. Once a solution is found, a local search is applied to update the value of the multiplier $\mu$, which is kept for more $k$ iterations of the subgradient method. These steps are conducted successively until a stop criterion is reached. This algorithm is described below. 


\section{Step 1. Initialization}

Define the initial value for $\mu$ and for $\lambda_{t}^{1}$ and $\lambda_{t}^{2}, t=1,2, \ldots, T$.

Let $k=1$ and cont $=0$.

\section{Step 2. Solution to the Problem}

Solve the $n$ lot-sizing subproblems.

Solve the transportation subproblem.

if the solution found is better than the current lower bound

$$
\begin{aligned}
& \text { then Update the current lower bound and let cont }=0 \text {; } \\
& \text { else } \quad \text { Let cont }=\text { cont }+1 \text {. }
\end{aligned}
$$

Calculate the subgradient.

if the solution obtained is feasible

$$
\begin{aligned}
& \text { then Update the upper bound; } \\
& \text { If the solution obtained is optimum then Stop. } \\
& \text { else Apply the smoothing heuristic. }
\end{aligned}
$$

Step 3. Apply 3 iterations of the one-dimensional search as proposed by Narciso (1998) to update the value of $\mu$.

Step 4. If cont $=15$ then update the subgradient step.

Update the values of $\lambda_{t}^{1}, t=1,2, \ldots, T$.

Let $k=k+1$.

If $k<$ num_Max_iterations

then $\quad$ Go back to Step 2.

else Stop.

The subgradient algorithm proposed by Held et al. (1974) was implemented in this study using the following criteria to update the subgradient step:

$$
\theta^{k}=\frac{\eta^{k}\left(U B-V\left(L_{\mu} S u_{\lambda}\right)\right)}{\left\|C X^{k}\right\|^{2}}
$$

where $v\left(L_{\mu} S u_{\lambda}\right)$ is the value of the objective function of the Lagrangian/surrogate relaxation in iteration $k, U B$ is an upper bound for the optimum solution to the problem (1)-(9), i.e., a feasible solution and $\eta^{k}$ is constant. The initial $\eta$ value is 1.75 . This value is kept for 15 iterations, and then it is divided by 2 and so on successively.

\subsection{Proposed Heuristic}

A heuristic based on the Lagrangian/surrogate relaxation was proposed for the solution of the problem studied. Given a feasible solution obtained via minimizing the Lagrangian/ surrogate problem, a smoothing heuristic is applied based on production transferring movements between periods to find a feasible solution to the problem. If a feasible solution is found, an improvement heuristics is applied. The smoothing heuristic is applied to each step of the subgradient algorithm. Changing Step 2 of the second algorithm presented in Section 3.1 for the following Step 2, we obtain our proposed heuristic. 


\section{Step 2. Solution to the Problem}

Solve the $n$ lot-sizing subproblems.

Solve the transportation subproblem.

if the solution found is better than the current lower bound

then $\quad$ Update the current lower bound and let cont $=0$;

else $\quad$ Let cont $=$ cont +1 .

Calculate the subgradient.

if the solution obtained is feasible

then Update the upper bound;

If the solution obtained is optimum then STOP.

else Apply the smoothing heuristic

If the current solution is feasible

then Apply the improvement heuristic.

\subsubsection{Smoothing Heuristic}

The smoothing heuristic is divided into two parts: the first is related to the capacity constraints, and the second is related to the container constraints.

\section{Smoothing procedure: Capacity constraints}

If the solutions found violate the set of capacity constraints at any period, it is necessary to transfer the production excess to a period with non-tight capacity. This transfer can be summarized in four steps:

- First step: it starts in the last period, focusing on transferring the production of items from periods with violated capacity to earlier periods.

- Second step: it also consists of transferring the production of items from periods, for which the capacity constraints are not met, but in this case, it starts at the first period and keeps going towards the period before the last period.

- These two steps are repeated once more and the capacity constraints are checked.

The transfer choice criterion to obtain a feasible solution is based on Toledo \& Armentano (2006) and consists of: giving the production excess in a period, a certain quantity of some item should be transferred to another period. The quantity to be transferred is calculated by taking, for that period, the minimum between the production excess and the quantity of the item produced. This calculation is done for every item and period that allows the transfer. The selection of the item and the period at which the production transfer occurs is obtained minimizing a function that considers the transfer costs and the production excess reduction. When a feasible solution is not found, a factor focuses on the excess reduction and gives less importance to the minimization of the transfer costs.

\section{Smoothing procedure: Container constraints}

The smoothing procedure used here was proposed by Norden \& Velde (2005). In each iteration of the relaxation algorithm, the transportation subproblem is used for coming up with a feasible solution. The goal is to find $A_{t}$ and $B_{t}$ that meet constraints (5) and (6). For each period, the items produced are allocated inside low cost containers whenever possible.

Pesquisa Operacional, v.29, n.2, p.269-288, Maio a Agosto de 2009 
The remaining items are allocated in high cost containers. Let $X_{i t}^{*}(i=1, \ldots, n$ and $t=1, \ldots, T)$ be an optimum solution for the lot-sizing subproblem. This is a feasible solution to the original problem if we use $A_{t}^{*}$ low cost containers and $B_{t}^{*}$ high cost containers where:

$$
A_{t}^{*}=\min \left\{R,\left\lceil\frac{1}{P} \sum_{i=1}^{n} X_{i t}^{*}\right\rceil\right\} \text { and } B_{t}^{*}=\max \left\{0,\left\lceil\frac{1}{P} \sum_{i=1}^{n} X_{i t}^{*}\right\rceil-R\right\} \text { for } t=1, \cdots, T \text {. }
$$

\subsubsection{Improvement Heuristic}

Two improvement heuristics were used. One is related to the transportation of containers and the other is related to lot-sizing.

\section{Improvement Procedure: Transportation of Containers}

Having a feasible solution, two steps are taken aiming at improving the solution without feasibility loss. In the first step, the periods are processed in increasing order, i.e., it can be observed from the first period to the last one in the planning horizon whether there is any period $t$ where $B_{t}>0$, which indicates the use of containers at period $t$ with $\operatorname{cost} c_{2}$. Next, the focus is to find a period $t$ ' after $t$, in which there are low cost $\left(c_{1}\right)$ containers that are not used at full capacity $\left(A_{t}, R\right)$. For a certain item $i$ produced in period $t$, the quantity to be transferred is calculated by taking the minimum between: the produced quantity of item $i$ in that period $t$; the quantity of items that can fit inside the low cost containers not used in the later period $t$ '; the quantity of items that can fit inside the high cost containers used in the later period $t$; and the remaining production capacity in period $t^{\prime}$.

After these evaluated transfers, we have a transfer possibility that keeps the solution feasibility. For a given possible transfer, the cost variation is calculated considering that the transfer actually occurs. To calculate the cost variation, the following can be considered: possible holding cost reduction; possible reduction or increase in the setup costs considering period $t$ and $t^{\prime}$; and possible reduction in the transportation costs. If the cost variation is negative, this item transfer is executed and if $B_{t}$ is still positive after the transfer, another item produced in the same period $t$ is searched for and a new transfer possibility is evaluated. If, after a transfer, $B_{t}$ is not positive, the next period is evaluated, and so on, searching for periods in which containers with $\operatorname{cost} c_{2}$ are being used.

The second step is similar to the first step, but it starts in the last period and moves towards the first one.

\section{Improvement Procedure: Lot-sizing}

Considering the Lagrangian relaxation of a problem, a solution of a relaxed problem is an optimum solution of the original problem, if this solution satisfies the complementary slackness conditions (Geoffrion, 1974). Thus, based on Araujo \& Arenales (2000), an improvement procedure was adapted focusing on solutions that are about to satisfy the complementary slackness conditions. Therefore, the production transfer from one period to another is made according to the following criteria: the transfer is made from period $t$, in which the Lagrangian multiplier $\lambda_{t}^{2}$ is equal to zero, for a period $k$ in which $\lambda_{k}^{2}$ is different from zero and with a slack of capacity. The transfer will occur only if the new solution is 
better than the earlier one and it takes place in two steps. The first one starts in the last period and moves towards the second. The second step starts in the first period and moves towards the period before the last period. The choice of the items and periods to do the transfer is made according to the values that maximize the following function:

$$
\text { Value before - After value }
$$

where:

- Value before: objective function value up to that moment;

- After value is the objective function value with the transfer of a certain item from period $t$ to period $k$.

The quantity $(w)$ to be transferred is:

$$
w=\min \left\{\operatorname{slack}(k)+\left(1-Y_{i k}\right) s_{i k}, X_{i t}\right\}
$$

where $\operatorname{slack}(k)$ is the non used capacity in period $k$.

\section{Computational Tests}

The computational tests were divided into two steps. In the first one, the model proposed by Norden \& Velde (2005) was considered, which does not have capacity constraints and does not allow backorder. The Lagrangian heuristic, developed by Norden \& Velde (2005), is compared to the Lagrangian/surrogate heuristic developed in this study. It can be noted that some modifications in the heuristic described in Section 3 should be considered, because in Norden and Velde's model capacity constraints and backlog are not considered. In the second one, the model (1)-(9) was considered and the capacity constraint effect was analyzed.

\subsection{Results for Norden \& Velde (2005)'s Model}

The Lagrangian heuristic proposed in the Norden \& Velde (2005) and the Lagrangian/ surrogate heuristic proposed in Section 3 were implemented using $\mathrm{C}$ language and compiled using the Borland $\mathrm{C}++$ version 5. The tests were run on a Pentium 4, 3GHz, 512MB RAM, under the operational system Windows XP. In order to obtain the optimum solutions used as a benchmark, the CPLEX 10.0 was used. The instances were generated based on the paper Norden \& Velde (2005). Hence, for all instances: $P=100, n=20, T=12$ (corresponding to the planning horizon of one year) and setup costs $s_{i t}=100$ for all items and periods.

Demands $d_{i t}$ were generated uniformly in the interval $\left.\left[\left\lfloor\frac{E D_{i}}{2}\right\rfloor, \mid \frac{3 E D_{i}}{2}\right\rceil\right]$, where $E D_{i}$ is the average demand generated uniformly in the interval $[40,700]$. In the process of data generating, there are demand peaks in the fifth and tenth period, where demand $d_{i t}$ is multiplied by 1.5. Two different combinations of transportation costs were generated: $c_{1}=50$ and $c_{2}=200$ and a more expensive combination given by $c_{1}=150$ and $c_{2}=500$. The maximum number of low cost containers, i.e. value $R$ is calculated according to the demand fraction that will be transported with $\operatorname{cost} c_{1}$. Value $F R$ means that $R$ should be generated in such a way that for $F R$ of the periods, the demand should be less than $R^{*} P$. The values of $F R$ used are $1 / 4$ and $1 / 6$. The holding costs are the same for all items and constants within the planning horizon. Two costs were considered: the low holding costs, $h=1$, and the high holding costs, $h=3$. 
For the procedures based on the Lagrangian relaxation and on Lagrangian/surrogate, a maximum number of iterations equal to 800 is considered. For the Lagrangian/surrogate, the initial Lagrangian multiplier value is $\mu=1$ and for each subgradient iteration the onedimensional search is applied during three iterations. For statistical analyses, 100 instances were generated for the computational tests considering each set of parameters $\left(F R, h, c_{1}, c_{2}\right)$. Considering the combination of some of these parameters, four groups of examples with the following characteristics were considered:

- Group 1: The first one with the total demand fraction equal to $1 / 6\left(F R=\frac{1}{6}\right)$ and transportation costs equal to $c_{1}=50$ and $c_{2}=200$;

- Group 2: The second group has the same demand fraction of the first group ( $F R=\frac{1}{6}$ ) and the transportation costs considered are $c_{1}=150$ and $c_{2}=500$;

- Group 3: The third group has the total demand fraction equal to $1 / 4\left(F R=\frac{1}{4}\right)$ and transportation costs equal to $c_{1}=50$ and $c_{2}=200$;

- Group 4: Lastly, the fourth group has the total demand fraction equal to $1 / 4\left(F R=\frac{1}{4}\right)$ and transportation costs equal to $c_{1}=150$ and $c_{2}=500$.

The results obtained were analyzed considering:

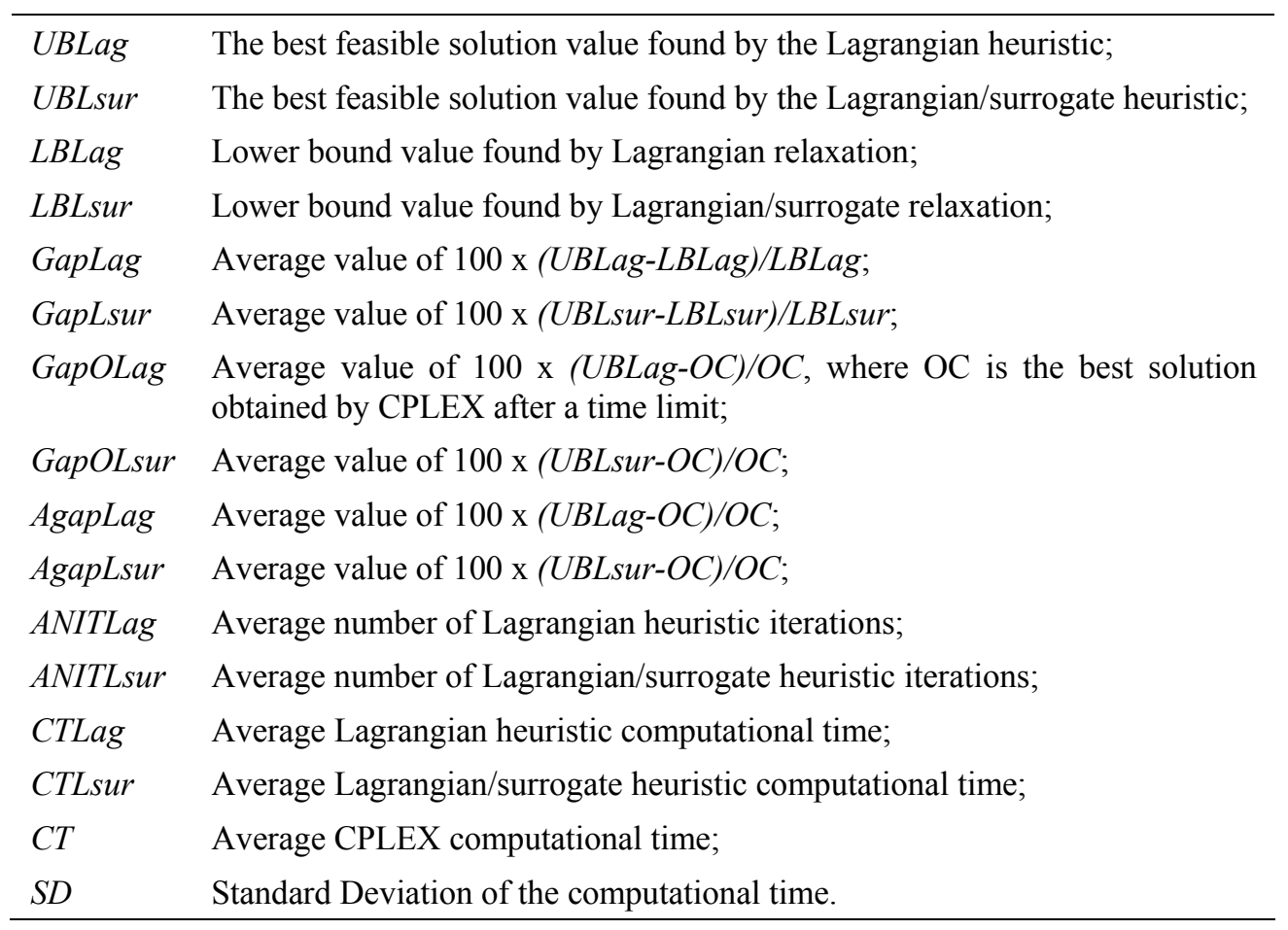


Table 1 shows the heuristic procedure results. The Lagrangian/surrogate heuristic presents solutions with average deviations smaller than the Lagrangian heuristic. Nevertheless, it cannot be said that the Lagrangian/surrogate heuristic is the best procedure for the problem since for both heuristics the stabilization and solution quality are quite similar despite the small improvement. Thus, it can be said that both approaches are competitive. In addition, Table 1 shows that the procedures have better gaps when more expensive transportation costs are considered (Groups 1 and 3).

The holding costs also affect the results found by the procedures and they are analyzed in Table 2, where group 3 is considered with various values for the holding cost.

Table 1 - Computational Results for Different parameters.

\begin{tabular}{|c|c|c|c|c|c|c|c|c|c|c|c|c|c|}
\hline & & \multicolumn{4}{|c|}{ Lagrangian } & \multicolumn{4}{c|}{ Lagrangian/surrogate } & CPLEX \\
\hline Prob. & h & GapLag & AgapLag & CTLag & ANITLag & GapOLag & GapLsur & AgapLsur & CTLsur & ANITLsur & GapOLsur & CT \\
\hline Group 1 & 1 & 0.99 & 1.77 & 0.08 & 714.14 & 8.10 & 0.99 & 1.77 & 0.21 & 722.08 & 8.10 & 299.85 \\
\hline Group 1 & 3 & 0.81 & 1.37 & 0.09 & 426.85 & 8.73 & 0.71 & 1.25 & 0.22 & 399.70 & 8.83 & 300.19 \\
\hline Group 2 & 1 & 1.05 & 1.70 & 0.08 & 651.55 & 3.32 & 1.06 & 1.70 & 0.21 & 657.31 & 3.32 & 300.26 \\
\hline Group 2 & 3 & 0.96 & 1.56 & 0.08 & 556.88 & 3.71 & 0.92 & 1.75 & 0.21 & 542.52 & 3.73 & 300.18 \\
\hline Group 3 & 1 & 1.04 & 1.65 & 0.09 & 734.41 & 8.30 & 1.04 & 1.70 & 0.22 & 738.51 & 8.29 & 298.75 \\
\hline Group 3 & 3 & 0.75 & 1.16 & 0.11 & 425.02 & 9.34 & 0.71 & 1.50 & 0.24 & 359.55 & 9.38 & 299.33 \\
\hline Group 4 & 1 & 1.11 & 1.97 & 0.09 & 729.92 & 3.41 & 1.12 & 1.91 & 0.22 & 726.54 & 3.41 & 300.22 \\
\hline Group 4 & 3 & 0.93 & 1.56 & 0.10 & 598.83 & 4.17 & 0.92 & 1.75 & 0.23 & 583.86 & 4.19 & 300.22 \\
\hline Average & $\mathbf{0 . 9 6}$ & $\mathbf{1 . 5 9}$ & $\mathbf{0 . 0 9}$ & $\mathbf{6 0 4 . 7 0}$ & $\mathbf{6 . 1 4}$ & $\mathbf{0 . 9 3}$ & $\mathbf{1 . 6 7}$ & $\mathbf{0 . 2 2}$ & $\mathbf{5 9 1 . 2 6}$ & $\mathbf{6 . 1 6}$ & $\mathbf{2 9 9 . 8 8}$ \\
\hline
\end{tabular}

Table 2 shows that for both procedures, it can be observed that the lower the holding costs $(h)$, the higher the average deviation, and the gaps found by the Lagrangian/surrogate heuristic (GapLsur) are better than the gaps from the Lagrangian heuristic (GapLag). Norden \& Velde (2005) already highlighted this holding cost effect. When considering the holding cost equal to zero, the heuristics developed determine, on average, better quality solutions than the CPLEX. However, for elevated holding costs, CPLEX obtain better quality solutions than the heuristic proposed. It is worth mentioning that the time limit for the CPLEX to obtain a solution was set to 300 seconds for the results presented in Tables 1 and 2 .

Table 2 - Computational Results for Different Holding Cost Values.

\begin{tabular}{|c|c|c|c|c|c|c|c|c|c|c|c|c|c|}
\hline & & \multicolumn{4}{|c|}{ Lagrangian } & \multicolumn{5}{c|}{ Lagrangian/surrogate } & CPLEX \\
\hline Prob. & $\mathrm{h}$ & GapLag & AgapLag & CTLag & ANITLag & GapOLag & GapLsur & AgapLsur & CTLsur & ANITLsur & GapOLsur & CT \\
\hline Group 3 & 0 & 2.75 & 4.29 & 0.15 & 794.98 & -0.51 & 2.70 & 4.17 & 0.30 & 794.74 & -0.47 & 300.25 \\
\hline Group 3 & 0.5 & 1.12 & 1.85 & 0.10 & 779.64 & 7.56 & 1.07 & 1.81 & 0.23 & 777.21 & 7.57 & 300.26 \\
\hline Group 3 & 1 & 1.04 & 1.65 & 0.09 & 734.41 & 8.29 & 1.04 & 1.70 & 0.22 & 738.51 & 8.29 & 298.82 \\
\hline Group 3 & 2 & 0.86 & 1.50 & 0.09 & 629.73 & 9.07 & 0.86 & 1.53 & 0.23 & 588.45 & 9.08 & 298.73 \\
\hline Group 3 & 3 & 0.75 & 1.16 & 0.11 & 425.02 & 9.35 & 0.71 & 1.50 & 0.23 & 359.55 & 9.38 & 299.30 \\
\hline Group 3 & 5 & 0.78 & 1.23 & 0.11 & 289.99 & 9.44 & 0.72 & 1.29 & 0.24 & 225.89 & 9.50 & 300.17 \\
\hline Group 3 & 10 & 0.78 & 1.31 & 0.11 & 274.33 & 9.49 & 0.59 & 1.28 & 0.24 & 270.83 & 9.70 & 295.31 \\
\hline Average & $\mathbf{1 . 1 5}$ & $\mathbf{1 . 8 6}$ & $\mathbf{0 . 1 1}$ & $\mathbf{5 6 1 . 1 6}$ & $\mathbf{7 . 5 3}$ & $\mathbf{1 . 1 0}$ & $\mathbf{1 . 9 0}$ & $\mathbf{0 . 2 4}$ & $\mathbf{5 3 6 . 4 5}$ & $\mathbf{7 . 5 8}$ & $\mathbf{2 9 8 . 9 8}$ \\
\hline
\end{tabular}




\subsection{Results for Model (1)-(9)}

The software used in these computational tests was the same used in the tests presented in Section 4.1. However, the computer used was a Pentium $43 \mathrm{GHz}, 1 \mathrm{GHHz}$ RAM.

The new data related to capacity restrictions were generated based on Trigeiro et al. (1989). The other data are similar to those described in Section 4.1. The production capacity in each period is generated depending on the production times and setup according to the following equation:

$$
\operatorname{Cap}_{t}=\left\lfloor\frac{\sum_{i=1}^{n} \sum_{k=1}^{T}\left(b_{i} d_{i k}+q_{i}\right)}{\alpha T}\right\rfloor t=1, \ldots, T ;
$$

where $\alpha$ is a parameter for slackness capacity control and two variations are considered: $\alpha=1$ and $\alpha=0.85$ representing, respectively, the tight and normal capacities.

For all items, the time required to produce a unit of item $i$ are given by $b_{i}=1$ and the setup times $\left(q_{i}\right)$ were generated randomly in the intervals $[10,50]$ and $[30,150]$. Finally, there are three possibilities for delay penalties $\left(h_{i t}^{-}\right): 5,10$, or 50 times the stock cost $\left(h_{i t}^{+}\right)$that was fixed in 1 or 3 .

Considering the parameters defined in this section and the ones defined in Section 4.1, for each parameter combination, 100 examples are generated. A total of 9,600 examples were generated in this second step of the computational tests.

The following two tables show the results of the tests run. The problems are shown in groups with the same characteristics of Groups 1, 2, 3, and 4 described in Section 4.1. However, each group represents a 12 parameter combination (two different stock costs combined with three types of delay penalties combined with two types of different setup times). Hence, for each relative line to a group, an average of 12 combinations of these groups is presented (100 examples for each combination are generated).

For the procedures based on the Lagrangian and Lagrangian/surrogate relaxation a maximum number of 800 iterations was considered. For Lagrangian/surrogate, the initial Lagrangian multiplier $\mu=1$ is considered and for each subgradient iteration, three iterations are applied in one-dimension searched.

Each table shows the resolution time (CPLEX was limited to $180 \mathrm{~s}$ in these tests), the best value obtained by CPLEX 10.0 optimization package in the time limit, the average number of iterations that the heuristics need to obtain the best solution, and the distance obtained by the heuristics in relation to the optimization.

Tables 3 and 4 show that both heuristics were again quite similar. The problem (1)-(9) can be considered more complicated due to capacity constraints and backlogging, the computational time and gap increased. A new column was included to compare the Standard Deviation (SD) of the computational time and both heuristics showed to be stable.

As expected, the heuristic needs less solution time than CPLEX. In addition, since the Lagrangian/surrogate heuristic has to make one-dimension search iterations, it needs more time than the Lagrangian heuristic. 
Table 3 - Results - Problems with tight capacity $(\alpha=1)$.

\begin{tabular}{|c|c|c|c|c|c|c|c|c|c|c|c|c|}
\cline { 2 - 17 } \multicolumn{1}{c|}{} & \multicolumn{9}{|c|}{ Lagrangian } & \multicolumn{4}{c|}{ Lagrangian/surrogate } \\
\hline Prob. & GapLag & AgapLag & CTLag & SD & ANITLag & GapOLag & GapLsur & AgapLsur & CTLsur & SD & ANITLsur & GapOLsur \\
\hline Group 1 & 30.63 & 44.83 & 16.89 & 1.81 & 173.84 & 29.77 & 28.69 & 47.95 & 17.50 & 2.08 & 165.36 & 28.44 \\
\hline Group 2 & 25.82 & 35.13 & 14.21 & 1.80 & 275.82 & 25.25 & 24.87 & 36.60 & 14.82 & 1.75 & 267.47 & 24.87 \\
\hline Group 3 & 31.23 & 48.33 & 16.31 & 1.34 & 177.36 & 30.22 & 29.47 & 52.48 & 16.78 & 1.34 & 148.82 & 29.07 \\
\hline Group 4 & 26.48 & 37.91 & 14.27 & 1.79 & 274.11 & 25.82 & 25.50 & 40.11 & 14.88 & 1.79 & 268.88 & 25.44 \\
\hline Average & $\mathbf{2 8 . 5 4}$ & $\mathbf{4 1 . 5 5}$ & $\mathbf{1 5 . 4 2}$ & $\mathbf{1 . 6 9}$ & $\mathbf{2 2 5 . 2 8}$ & $\mathbf{2 7 . 7 7}$ & $\mathbf{2 7 . 1 3}$ & $\mathbf{4 4 . 2 8}$ & $\mathbf{1 6 . 0 0}$ & $\mathbf{1 . 7 4}$ & $\mathbf{2 1 2 . 6 3}$ & $\mathbf{2 6 . 9 5}$ \\
\hline
\end{tabular}

Considering the normal capacity (Table 4), it can be seen that the heuristics need less iterations to obtain the upper bound and it obtains a better upper bound. The results for the other data variations follow the same pattern of the results of the tight capacity problems.

Table 4 - Results - Problems with normal capacity $(\alpha=0,85)$.

\begin{tabular}{|c|c|c|c|c|c|c|c|c|c|c|c|c|}
\hline & \multicolumn{6}{|c|}{ Lagrangian } & \multicolumn{6}{|c|}{ Lagrangian/surrogate } \\
\hline Prob. & GapLag & AgapLag & CTLag & SD & ANITLag & GapOLag & GapLsur & AgapLsur & CTLsur & SD & ANITLsur & GapOLsur \\
\hline Group 1 & 22.12 & 31.73 & 10.81 & 2.31 & 69.86 & 19.89 & 21.48 & 32.49 & 12.13 & 1.67 & 34.31 & 19.94 \\
\hline Group 2 & 22.28 & 28.37 & 10.22 & 2.21 & 113.82 & 21.17 & 22.13 & 29.87 & 11.01 & 2.02 & 77.57 & 21.20 \\
\hline Group 3 & 22.92 & 41.74 & 10.78 & 2.20 & 60.97 & 20.42 & 22.23 & 41.30 & 11.98 & 1.52 & 30.11 & 20.42 \\
\hline Group 4 & 22.93 & 30.85 & 10.23 & 2.16 & 114.25 & 21.58 & 22.76 & 31.50 & 11.06 & 1.90 & 66.60 & 21.61 \\
\hline Average & 22.56 & 33.17 & 10.51 & 2.22 & 89.73 & 20.77 & 22.15 & 33.79 & 11.54 & 1.78 & 52.15 & 20.79 \\
\hline
\end{tabular}

As seen in Section 4.1 to the problem proposed by Norden \& Velde (2005), the heuristics are competitive and the heuristic Lagrangian/surrogate produce gaps lower than the Lagrangian. However, we can not say that the Lagrangian/surrogate procedure is the best procedure for the problem (1)-(9), i.e., the analysis remains valid to the procedures outlined in Section 4.1.

\section{Conclusions}

The aim of this study was to evaluate the efficiency of the Lagrangian/surrogate approach for the integrated lot-sizing and distribution problem. The problem studied involves production and transportation planning of various items in a planning horizon of $T$ periods. The objective is to minimize setup, production, inventory and transportation costs. Transporting items involves a contract established for the whole planning horizon and it has a fixed cost, a reduced cost for a fixed number of contracted containers, and the possibility of contracting additional containers at an elevated cost. The number of contracted containers is estimated based on the planning horizon demand forecast.

The model proposed is an extension of a literature model considering delays in meeting the demand and capacity constraints. A heuristic based on the Lagrangian/surrogate relaxation was proposed for solving the problem. Initially, the results obtained were compared to the Lagrangian heuristic proposed by Norden \& Velde (2005) for the problem originally proposed by these authors. The two heuristics results are similar in the deviation of the optimum solution to the problems. In a second step of the computational tests, the model extension proposed was studied and the results indicate that in the case of tight capacity 
constraints, the results of the Lagrangian/surrogate heuristic are better than the Lagrangian heuristic results. It can be concluded that the approach proposed is competitive, which stimulates the study of its application in other lot-sizing and distribution problems.

\section{Acknowledgements}

The authors would like to thank the anonymous referees for their useful comments and suggestions. This research was partially funded by the Fundação de Amparo a Pesquisa do Estado de São Paulo (FAPESP), Conselho Nacional de Desenvolvimento Científico e Tecnológico (CNPq) and Coordenação de Aperfeiçoamento de Pessoal de Nível Superior (CAPES).

\section{References}

(1) Araujo, S.A. \& Arenales, M.N. (2000). Problema de Dimensionamento de Lotes Monoestágio com Restrição de Capacidade: modelagem, método de resolução e resultados computacionais. Pesquisa Operacional, 20, 2, 287-306.

(2) Baumol, W.J. \& Vinod, H.D. (1970). An inventory theoretic model of freight transport demand. Management Science, 16, 413-421.

(3) Bertazzi, L. \& Speranza, M.G. (1999). Models and Algorithms for the Minimization of Inventory and Transportation Costs: A Survey. In: New Trends in Distribution Logistics (edited by M.G. Speranza and P. Staehly), Lecture Notes in Economics and Mathematical Systems, Vol. 480, pp. 137-157, Springer-Verlag, Berlin Heidelberg.

(4) Brahimi, N.; Dauzere-Peres, S.; Najid, N.M. \& Nordi, A. (2006), Single Item Lot Sizing Problems. European Journal of Operational Research, 168, 1-16.

(5) Diaby, M.; Bahl H.; Karwan, M.H. \& Ziont, S. (1992). Capacitated Lot-Sizing and Scheduling by Lagrangean Relaxation. European Journal of Operational Research, 59, 444-458.

(6) Erenguç, S.S.; Simpson, N.C. \& Vakharia, A.J. (1999). Integrated production/ distribution planning in supply chains? An invited review. European Journal of Operational Research, 115, 219-236.

(7) Fisher, M.L. (1981). The Lagrangian relaxation method for solving integer programming problems. Management Science, 27, 1-18.

(8) Geoffrion, A.M. (1974). Lagrangian relaxation in integer programming. Mathematical Programming Study, 2, 82-114.

(9) Glover, F. (1965). A multiphase dual algorithm for the zero-one integer programming problem. Operations Research, 13, 879-919.

(10) Glover, F. (1968). Surrogate Constraints. Operations Research, 16(4), 741-749.

(11) Glover, F. (1975). Surrogate Constraints Duality in Mathematical Programming. Operations Research, 23, 434-451.

(12) Greenberg, H.J. \& Pierskalla, W.P. (1970). Surrogate Mathematical Programming. Operations Research, 18, 924-939. 
(13) Greenberg, H.J. \& Pierskalla, W.P. (1973). Quasi-conjugate Functions and Surrogate Duality. Cahiers Centre Études de Rech. Oper., 15, 437-448.

(14) Held, M.; Wolfe, P. \& Croweder, H. (1974). Validation of Subgradient Optimization. Mathematical Programming, 6, 62-68.

(15) Held, M. \& Karp, R.M. (1971). The traveling salesman problem and minimum spanning tress: part II. Mathematical Programming, 1, 6-25.

(16) Karimi, B.; Ghomi, S.M.T.F. \& Wilson, J.M. (2003). The capacitated lot sizing problem: a review of models and algorithms. Omega, 31, 365-378.

(17) Karwan, M.L. \& Rardin, R.L. (1979). Some Relationships Between Lagrangean and Surrogate Duality in Integer Programming. Mathematical Programming, 17, 320-334.

(18) Lee, C.Y. (1989). A solution to the multiple set-up problem with dynamic demand. IIE Transactions, 21, 266-270.

(19) Lee, W.-S.; Han, J.H. \& Cho, S.J. (2005). A heuristic for a multi-product dynamic lotsizing and shipping problem. Int. J. Production Economics, 98, 204-214.

(20) Lorena, L.A.N. \& Pereira, M.A. (2002). A lagrangean/surrogate heuristic for the maximal covering problem using Hillsman's edition. International Journal of Industrial Engineering, 9(1), 57-67.

(21) Lozano, S.; Larraneta, J. \& Oliveira, L. (1991). Primal Dual Approach to the Single Level Capacitated Lot-Sizing Problem. European Journal of Operational Research, 51, 354-366.

(22) Narciso, M.G. (1998). A relaxação Lagrangeana/Surrogate e algumas aplicações em otimização combinatória. Tese de Doutorado em Computação Aplicada, INPE, São José dos Campos.

(23) Narciso, M.G. \& Lorena, L.A.N. (1999). Lagrangean/Surrogate relaxation for generalized assignment problem. European Journal of Operational Research, 114, 165-177.

(24) Norden, L. van \& Velde, S. van de (2005). Multi-product lot-sizing with a transportation capacity reservation contract. European Journal of Operational Research, 165, 127-138.

(25) Oliveira, L.K. \& Morabito, R. (2006). Métodos Exatos Baseados em Relaxações Lagrangiana e Surrogate para o Problema de Carregamento de Paletes do Produtor. Pesquisa Operacional, 26, 403-432.

(26) Rizk, N. \& Martel, A. (2001). Supply chain flow planning methods: a review of the lotsizing literature. Working Paper DT-2001-AM-1, Université Laval, QC, Canada.

(27) Senne, E.L.F. \& Lorena, L.A.N. (2000). Lagrangean/Surrogate Heuristics for p-Median Problems. In: Computing Tools for Modeling, Optimization and Simulation: Interfaces in Computer Science and Operations Research [edited by M. Laguna and J.L. GonzalezVelarde], Kluwer Academic Publishers, 115-130.

(28) Toledo, F.M.B. \& Armentano, V.A. (2006). A Lagrangian-based heuristic for the capacitated lot-sizing problem in parallel machines. European Journal of Operational Research, 175, 1070-1083. 
(29) Trigeiro, W.W.; Thomas, L.J. \& Mcclain, J.O. (1989). Capacitated Lot Sizing With Setup Times. Management Science, 35(3), 353-366.

(30) Vroblefski, M.; Ramesh, R. \& Zionts, S. (2000). Efficient lot-sizing under a differential transportation cost structure for serially distributed ware-houses. European Journal of Operational Research, 127, 574-593.

(31) Wagner, H.M. \& Whitin, T.M. (1958). Dynamic version of the economic lot size model. Management Science, 5, 89-96. 